\title{
In vitro Antiplasmodial Activities of Alkaloids Isolated from Roots of Worsleya procera (Lem.) Traub (Amaryllidaceae)
}

\author{
Karla L. Gonring-Salarini, ${ }^{a}$ Raphael Conti, ${ }^{b}$ Jean Paulo de Andrade, ${ }^{a}$ \\ Bárbara Juliana P. Borges, ${ }^{a}$ Anna Caroline C. Aguiar, ${ }^{c}$ Juliana O. de Souza, ${ }^{c}$ \\ Camila L. Zanini, ${ }^{c}$ Glaucius Oliva, ${ }^{c}$ Juan Carlos Tenorio, ${ }^{d}$ Javier Ellena, ${ }^{d}$ \\ Jaume Bastida, ${ }^{e}$ Rafael V. C. Guido ${ }^{*, c}$ and Warley de S. Borges ${ }^{\circledR} *, a, b$ \\ ${ }^{a}$ Departamento de Ciências Farmacêuticas, Universidade Federal do Espírito Santo (UFES), \\ Av. Marechal Campos, 1468, 29043-900 Vitória-ES, Brazil \\ ${ }^{b}$ Departamento de Química, Universidade Federal do Espírito Santo (UFES), \\ Av. Fernando Ferrari, 514, 29075-910 Vitória- ES, Brazil \\ 'Instituto de Física de São Carlos, Universidade de São Paulo (USP), \\ Av. João Dagnone, 1100, 13563-120 São Carlos-SP, Brazil \\ ${ }^{d}$ Laboratório Multiusuário de Cristalografia Estrutural, Instituto de Física de São Carlos, \\ Universidade de São Paulo (USP), Av. Trabalhador São Carlense, 400, \\ CP 369, 13560-570 São Carlos-SP, Brazil
}

${ }^{e}$ Department de Biologia, Sanitat i Medi Ambient, Facultat de Farmàcia, Universitat de Barcelona, Av. Joan XXIII 27-31, 08028 Barcelona, Spain

\begin{abstract}
A combined phytochemical, crystallographic and biological study of Worsleya procera roots was performed. Fifteen alkaloids were identified by gas chromatography mass spectrometry (GC-MS) and seven of them were isolated. The structures of the alkaloids were elucidated by spectroscopic methods, and a detailed crystallographic study of tazettine was carried out. The isolated alkaloids and the obtained extracts were tested in vitro against Plasmodium falciparum (3D7 and K1 strains) and human hepatocarcinoma cells (HepG2) to assess their antiplasmodial and cytotoxic effects, respectively. One of the isolated alkaloid derivatives, lycorine, exhibited antiplasmodial activity against both sensitive (3D7) and resistant (K1) parasite strains in the low micromolar range (half-maximal sample inhibitory concentration $\left(\mathrm{IC}_{50}\right)$ values of 2.5 and $3.1 \mu \mathrm{M}$, respectively) and displayed a low cytotoxicity profile, with a selectivity index greater than 100 . Our findings indicate that lycorine is a hit for antimalarial drug discovery.
\end{abstract}

Keywords: isoquinolinic alkaloids, Amaryllidaceae, Plasmodium falciparum, lycorine, tazettine

\section{Introduction}

Malaria is one of the most relevant infectious diseases throughout the world. For decades, global efforts towards malaria eradication reflected in a yearly decrease in cases and mortality rates. Since 2016, however, the rate of malaria infections is rising due to resistance in both the parasite and the mosquito vectors to antimalarial drugs and insecticides, respectively. ${ }^{1}$ Artemisinin-based combination therapies (ACTs), employing artemisinin

*e-mail: rvcguido@usp.br; warley.borges@ufes.br and its derivatives (dihydroartemisinin, artemether and artesunate), remain as the standard treatment against falciparum malaria. However, the emergence and spread of resistance are constant threats, as cases of parasite resistance to ACTs have been reported as early as 2008. ${ }^{2}$ Hence, the efficiency of drugs in use has been declining, despite investment from organizations such as the Bill and Melinda Gates Foundation and national governments. Unquestionably, there is a demand for new and effective drugs for malaria treatment.

Natural products play an important role in the discovery process of new drugs. ${ }^{3}$ Brazilian biodiversity 
has an enormous potential for the discovery of new natural products endowed with innovative molecular scaffolds and activity against various diseases. ${ }^{4-7}$ In this sense, plants of the Amaryllidaceae family are promising sources of bioactive molecules. ${ }^{8-20}$ Comprising more than 1600 species worldwide, the Amaryllidaceae family is distinguished by the production of isoquinolinic alkaloids, a privileged scaffold responsible for most of the biological activities observed in these plants. This kind of alkaloids is specifically found in the Amaryllidoideae subfamily species. In Brazil, according to Rio de Janeiro's Botanical Garden, ${ }^{21} 142$ species of Amaryllidaceae have been described, of which 64 are endemic and some are endangered, as is the case of Worsleya procera (Lem.) Traub, ${ }^{22}$ the only representative of the genus Worsleya. ${ }^{18,23-26}$ This species occurs exclusively in the State of Rio de Janeiro (Brazil) and no phytochemical study has been reported for this species so far.

In this work, we performed a combined strategy including phytochemical, crystallographic and biological studies to better characterize the isolated alkaloids from Worsleya procera. We investigated the roots' extracts for their chemical composition, identified fifteen alkaloids by gas chromatography mass spectrometry (GC-MS), and isolated seven derivatives. Next, we conducted crystallographic studies and solved the molecular structure of tazettine at high resolution. All isolated alkaloids and the obtained extracts were tested in vitro for their antiplasmodial potency against Plasmodium falciparum, as well as for their cytotoxic effect in human hepatoma cells (HepG2). The most potent alkaloid derivative, lycorine, is a low micromolar inhibitor of both sensitive and resistant strains of $P$. falciparum and has considerable safety profile against human cells.

\section{Experimental}

\section{Plant material}

Roots of Worsleya procera were collected in Petropolis city (State of Rio de Janeiro, Brazil) in July 2014. The plant was collected in an area of environmental protection (22 32'38.7''S 4310'11.8' $\mathrm{W}$ ); therefore, an authorization for sampling was issued by the proper regulatory agencies (Sistema de Autorização e Informação em Biodiversidade (SISBIO) No. 41717). The sample was authenticated by Dr Julie H. A. Dutilh from University of Campinas (Unicamp, Campinas city, Brazil). A specimen voucher (No. 35307) was deposited in the Herbarium VIES of the Department of Botany of the Federal University of Espírito Santo (Vitória city, Brazil).

\section{Equipment}

The GC-MS spectra were obtained on a GC-17A Shimadzu CG-MS QP 5000 operating in the EI mode at $70 \mathrm{eV}$ using a DB5 MS column $(30 \mathrm{~m} \times 0.25 \mathrm{~mm} \times 0.25 \mu \mathrm{m})$. The temperature program was as it follows: $100-180{ }^{\circ} \mathrm{C}$ at $15{ }^{\circ} \mathrm{C} \mathrm{min}-1,1 \mathrm{~min}$ hold at $180{ }^{\circ} \mathrm{C}$, then $180-300{ }^{\circ} \mathrm{C}$ at $5{ }^{\circ} \mathrm{C} \mathrm{min}-1$ and $10 \mathrm{~min}$ hold at $300{ }^{\circ} \mathrm{C}$. The injector temperature was $280{ }^{\circ} \mathrm{C}$. The flow rate of carrier gas (helium) was $0.8 \mathrm{~mL} \mathrm{~min}{ }^{-1}$ and the split ratio was 1:20.

The alkaloids were identified by comparing their GC-MS spectra and Kovats retention indices (RI) with our library database. This library has been regularly updated with alkaloids isolated and unequivocally identified via physical and spectroscopic means. ${ }^{27-29}$ Mass spectra were deconvoluted using AMDIS 2.64 software (NIST) (WA, USA) and RIs recorded using a standard $n$-hydrocarbon calibration mixture (C9-C36). The proportion of individual components in the alkaloid fractions is expressed as a percentage of total alkaloid content. GC-MS peak areas are dependent on the concentration of the injected alkaloid, as well as the intensity of its mass spectral fragmentation. Although the data given in Table 1 are not representative of a validated alkaloid quantification method, they can be used for a relative comparison purpose.

Nuclear magnetic ressonance (NMR) spectra were recovered in a Varian $400 \mathrm{MHz}$ instrument using $\mathrm{CDCl}_{3}\left(\mathrm{CD}_{3} \mathrm{OD}\right.$ for compound 11) as a solvent and tetramethylsilane (TMS) as the internal standard. Chemical shifts were reported in $\delta$ units (ppm) and coupling constants $(J)$ in $\mathrm{Hz}$.

Silica gel (120 g, mesh 70/90 $\mu \mathrm{m})$ was used for vacuum liquid chromatography column (VLCC), and silica gel 60 F254 Macherey-Nagel for analytics and prep. Spots on chromatograms were detected under UV light (254 nm) and by Dragendorff's reagent stain.

\section{Extraction and isolation of alkaloids}

Fresh roots $(6.7 \mathrm{Kg})$ of Worsleya procera were crushed and exhaustively extracted with $\mathrm{MeOH}(100 \% \mathrm{v} / \mathrm{v})$ at room temperature for $48 \mathrm{~h}$, and the combined macerate was filtered and evaporated to dryness under reduced pressure. The crude extract of roots (146.2 g) was acidified to $\mathrm{pH} 2$ with diluted sulphuric acid $\left(\mathrm{H}_{2} \mathrm{SO}_{4}\right)$ and extracted with diethyl ether $\left(\mathrm{Et}_{2} \mathrm{O}\right)(3 \times 150 \mathrm{~mL})$ to remove neutral material. The aqueous solution was basified with $25 \%$ ammonia $\left(\mathrm{NH}_{3}\right)$ up to $\mathrm{pH} 10$ and extracted with $n$-hexane $(18 \times 250 \mathrm{~mL})$ to give extract A $(2.9368 \mathrm{~g})$. Another extraction using ethyl acetate $($ EtOAc) $(18 \times 350 \mathrm{~mL})$ gave extract B (6.9987 g), and the last extraction using EtOAc 
Table 1. GC-MS data for Worsleya procera, values are expressed as a relative percentage of total ion current (TIC)

\begin{tabular}{|c|c|c|c|c|c|}
\hline \multirow{2}{*}{ Alkaloid } & \multirow{2}{*}{ RI } & \multicolumn{2}{|c|}{ Enriched fractions / \% } & \multirow{2}{*}{$\mathrm{M}^{+}$} & \multirow{2}{*}{ MS } \\
\hline & & $n-\mathrm{Hex} / \%$ & EtOAc / \% & & \\
\hline Ismine (1) & 2280 & 3.2 & 5.8 & $257(35)$ & 238(100), 211(6), 196(8), 168(6), 154(3), 106(4), 77(3) \\
\hline Trisphaeridine (2) & 2282 & $\operatorname{tr}$ & $\operatorname{tr}$ & $223(100)$ & 222(38), 167(8), 165(9), 164(14), 138(20), 137(9), 111(13) \\
\hline 5,6-Dihydrobicolorine (3) & 2327 & $\operatorname{tr}$ & $\operatorname{tr}$ & $239(45)$ & 238(100), 180(30), 166(10), 152(22), 139(21), 118(21), 90(31) \\
\hline Galanthindole (4) & 2487 & - & 12.8 & $281(100)$ & 280(7), 264(13), 263(17), 262(20), 252(15), 204(7), 1(14), 132(8) \\
\hline$O$-Methyllycorenine (5) & 2492 & 4.0 & $\operatorname{tr}$ & $331(<1)$ & 300(3), 191(8), 147(1), 110(8), 109(100), 94(3), 77(1) \\
\hline 7-Methoxy-O-methyllycorenine (6) & 2538 & 2.4 & - & $361(<1)$ & $330(8), 221(10), 191(2), 110(8), 109(100), 108(15), 94(2), 83(2)$ \\
\hline Undefined - homolycorine-type derivative & 2597 & $\operatorname{tr}$ & - & nd & 330(2), 221(5), 110(8), 109(100), 108(16), 94(5), 82(3), 42(3) \\
\hline Ungwedine derivative & 2598 & $\operatorname{tr}$ & $\operatorname{tr}$ & nd & $\begin{array}{c}330(18), 314(10), 261(100), 239(34), 238(25), 228(31), 128(30), \\
44(20)\end{array}$ \\
\hline 11,12-Dehydroanhydrolycorine (7) & 2606 & - & $\operatorname{tr}$ & 249(60) & 248(100), 190(32), 189(10), 163(10), 123(13), 95(30), 81(9) \\
\hline Tazettine $(\mathbf{8})$ /pretazettine $(\mathbf{9})$ & 2653 & 16.7 & 18.3 & $331(31)$ & 316(15), 298(23), 247(100), 230(12), 201(15), 181(11), 152(7) \\
\hline Galanthine (10) & 2720 & 1.9 & 19.6 & $317(22)$ & $316(15), 298(10), 268(18), 243(96), 242(100), 228(8)$ \\
\hline Lycorine (11) & 2746 & $\operatorname{tr}$ & 13.19 & $287(31)$ & 286(19), 268(24), 250(15), 227(79), 226(100), 211(7), 147(15) \\
\hline Homolycorine (12) & 2767 & 8.9 & 4.8 & $315(<1)$ & $206(<1), 178(2), 109(100), 150(1), 108(22), 94(3), 82(3)$ \\
\hline 3-epi-Macronine (13) & 2811 & 6.10 & $\operatorname{tr}$ & $329(27)$ & $314(23), 245(100), 225(14), 201(83), 139(16), 70(18)$ \\
\hline Albomaculine (14) & 2815 & 15.4 & 14.9 & $345(<1)$ & $221(1), 193(1), 165(1), 110(10), 109(100), 108(25), 94(2), 82(3)$ \\
\hline Undefined - homolycorine-type derivative & 2870 & $\operatorname{tr}$ & - & nd & 178(7), 150(4), 140(9), 138(88), 124(100), 96(14), 94(10) \\
\hline Hippeastrine (15) & 2917 & - & $\operatorname{tr}$ & $315(<1)$ & 190(1), 163(1), 134(3), 126(8), 125(100), 124(9), 96(40), 77(2) \\
\hline Sterols derivatives & - & 3.19 & - & & - \\
\hline Neutral metabolites & - & 36.1 & 5.8 & & - \\
\hline
\end{tabular}

GC-MS: gas chromatography mass spectrometry; RI: Kovats retention indices; tr: traces (less than 1\% of TIC); sterols derivatives: including stigmasterol, sitosterol, among others; neutral metabolites: including terpens, fatty acids, among others; nd: not detected.

and methanol $(\mathrm{MeOH})(3: 1,3 \times 200 \mathrm{~mL})$ gave extract $\mathrm{C}$ (7.7210 g).

Extract A yielded lycorine $(\mathbf{1 1}, 42.3 \mathrm{mg})$ by spontaneous precipitation. The supernatant was subjected to a VLCC column (Ø: $3 \mathrm{~cm})$ using silica gel (120 g, mesh 70/90 $\mu \mathrm{m})$ eluting with $n$-hexane gradually enriched with EtOAc $(0 \rightarrow 100 \%)$, and then with $\mathrm{MeOH}(0 \rightarrow 50 \%)$. Samples of $200 \mathrm{~mL}$ were collected (44 in total) and monitored by thin layer chromatography (TLC) (Dragendorff's reagent, UV light $\lambda 254 \mathrm{~nm}$ ) and combined according to their TLC profiles, obtaining four fractions: 1-4 (fraction I), 5-8 (fraction II), 9-34 (fraction III) and 35-44 (fraction IV). Fraction I (343.4 mg) was subjected to a liquid chromatography column (LCC) (Ø: $1 \mathrm{~cm}$ ) using $400 \mathrm{~mL}$ of $n$-hexane:acetone (1:1), $350 \mathrm{~mL}$ of $n$-hexane:acetone (1:4), $300 \mathrm{~mL}$ of $n$-hexane:acetone:dichloromethane $(2: 1: 1), 250 \mathrm{~mL}$ of acetone:dichloromethane $\left(\mathrm{CH}_{2} \mathrm{Cl}_{2}\right)(1: 1)$ and $200 \mathrm{~mL}$ of acetone: $\mathrm{CH}_{2} \mathrm{Cl}_{2}: \mathrm{MeOH}$ (1:1:1), providing 150 samples. After combining samples 27-45, preparative thin layer chromatography (PTLC) $(20 \mathrm{~cm} \times 20 \mathrm{~cm} \times 0.25 \mathrm{~mm}$, silica gel F254, $n$-hexane:acetone: $\mathrm{CH}_{2} \mathrm{Cl}_{2}(1: 1: 2)$, v/v/v in $\mathrm{NH}_{3}$ atmosphere) was used to isolate trisphaeridine (2, $18.9 \mathrm{mg}$ ). Fraction II (271.0 mg), was subjected to a LCC
(Ø: $1 \mathrm{~cm}$ ) using $150 \mathrm{~mL}$ of $n$-hexane:acetone: $\mathrm{CH}_{2} \mathrm{Cl}_{2}$ (2:1:1), $200 \mathrm{~mL}$ of $n$-hexane:acetone: $\mathrm{CH}_{2} \mathrm{Cl}_{2}: \mathrm{MeOH}$ (3:3:1:2) and $250 \mathrm{~mL}$ acetone: $\mathrm{MeOH}(1: 1)$, providing 83 samples. After combining samples 14-22 and 23-83, PTLC $(20 \mathrm{~cm} \times 20 \mathrm{~cm} \times 0.25 \mathrm{~mm}$, silica gel F254, $n$-hexane:acetone: $\mathrm{CH}_{2} \mathrm{Cl}_{2}: \mathrm{MeOH}(3: 3: 1: 2)$, v/v/v/v in $\mathrm{NH}_{3}$ atmosphere) was used to isolate tazettine $(\mathbf{8}, 19.2 \mathrm{mg})$ and 3-epi-macronine (13, $28.9 \mathrm{mg})$, respectively. Fraction III $(1227.5 \mathrm{mg})$, was subjected to a LCC (Ø: $2 \mathrm{~cm})$ using $450 \mathrm{~mL}$ of $n$-hexane:AcOEt: $\mathrm{CH}_{2} \mathrm{Cl}_{2}(2: 1: 2), 500 \mathrm{~mL}$ of $n$-hexane:AcOEt: $\mathrm{CH}_{2} \mathrm{Cl}_{2}: \mathrm{MeOH}(2: 1: 2: 1), 550 \mathrm{~mL}$ of acetone: $\mathrm{CH}_{2} \mathrm{Cl}_{2}: \mathrm{MeOH}(2: 2: 1)$ and $400 \mathrm{~mL}$ of acetone:MeOH (1:1), providing 493 samples. After combining samples 1-93, another LCC (Ø: $1 \mathrm{~cm})$ was applied using $100 \mathrm{~mL}$ of $n$-hexane:AcOEt (2:1), $200 \mathrm{~mL}$ of $n$-hexane:AcOEt:MeOH (2:4:1) and $n$-hexane:AcOEt: $\mathrm{CH}_{2} \mathrm{Cl}_{2}: \mathrm{MeOH}$ (1:2:1:1), providing 80 samples. After combining samples 55-79, PTLC $(20 \mathrm{~cm} \times 20 \mathrm{~cm} \times 0.25 \mathrm{~mm}$, silica gel F254, $n$-hexane:AcOEt: $\mathrm{CH}_{2} \mathrm{Cl}_{2}$ :acetone:MeOH (1:2:2:1:1), $\mathrm{v} / \mathrm{v} / \mathrm{v} / \mathrm{v} / \mathrm{v}$ in $\mathrm{NH}_{3}$ atmosphere) was used to isolate homolycorine $(\mathbf{1 2}, 10.7 \mathrm{mg})$ and albomaculine $(\mathbf{1 4}, 15.5 \mathrm{mg})$. Samples 170-210, from fraction III, were subjected to another LCC (Ø: $1 \mathrm{~cm})$ using $100 \mathrm{~mL}$ of $n$-hexane:AcOEt 
(2:1), $150 \mathrm{~mL}$ of $n$-hexane:AcOEt:acetone (4:2:1), $200 \mathrm{~mL}$ of $n$-hexane:acetone: $\mathrm{CH}_{2} \mathrm{Cl}_{2}: \mathrm{MeOH}$ (2:1:2:1), $200 \mathrm{~mL}$ of acetone: $\mathrm{CH}_{2} \mathrm{Cl}_{2}: \mathrm{MeOH}(2: 1: 1), 250 \mathrm{~mL}$ of acetone:MeOH (1:1) providing 113 samples. After combining samples 22-37, PTLC $(20 \mathrm{~cm} \times 20 \mathrm{~cm} \times 0.25 \mathrm{~mm}$, silica gel F254, $n$-hexane:AcOEt: $\mathrm{CH}_{2} \mathrm{Cl}_{2}$ :acetone:MeOH $(1: 2: 2: 1: 1), \mathrm{v} / \mathrm{v} / \mathrm{v} / \mathrm{v} / \mathrm{v}$ in $\mathrm{NH}_{3}$ atmosphere) was used to isolate more homolycorine $(\mathbf{1 2}, 8.1 \mathrm{mg})$. Samples 350-420, from fraction III, were subjected to PTLC $(20 \mathrm{~cm} \times 20 \mathrm{~cm} \times 0.25 \mathrm{~mm}$, silica gel F254, AcOEt:acetone: $\mathrm{MeOH}(2: 1: 1), \mathrm{v} / \mathrm{v} / \mathrm{v}$ in $\mathrm{NH}_{3}$ atmosphere) was used to isolate more tazettine $(\mathbf{8}, 14.6 \mathrm{mg})$. Fraction IV $(565.4 \mathrm{mg})$ was subjected to an LCC (Ø: $2 \mathrm{~cm})$ eluting with $n$-hexane gradually enriched with EtOAc $(0 \rightarrow 100 \%)$, and then with $\mathrm{MeOH}(0 \rightarrow 50 \%)$, providing 285 samples. After combining samples 101-156, another LCC (Ø: $1 \mathrm{~cm})$ was employed, using the same elution system as previously described, providing 215 samples. From samples 11-37, tazettine $(\mathbf{8}, 46.5 \mathrm{mg})$ was isolated again by crystallization with AcOEt. From samples 154-177, ismine (1, $13.1 \mathrm{mg})$ was isolated by precipitation, and from samples 178-202, more homolycorine $(\mathbf{1 2}, 12.8 \mathrm{mg})$ was isolated by precipitation.

Extract B yielded lycorine $(\mathbf{1 1}, 504.9 \mathrm{mg})$ by spontaneous precipitation. The supernatant was subjected to a VLCC (Ø: $5 \mathrm{~cm})$ using silica gel $(250 \mathrm{~g}$, mesh $70 / 90 \mu \mathrm{m})$ eluting with $n$-hexane gradually enriched with EtOAc $(0 \rightarrow 100 \%), \mathrm{CH}_{2} \mathrm{Cl}_{2}: \mathrm{MeOH}(1: 1,0 \rightarrow 50 \%)$, and then with $\mathrm{MeOH}(0 \rightarrow 50 \%)$. Samples of $400 \mathrm{~mL}$ were collected (35 in total) monitored by TLC (Dragendorff's reagent, UV light $\lambda 254 \mathrm{~nm}$ ) and combined according to their TLC profiles, obtaining six fractions: 1-13 (fraction I), 14-18 (fraction II), 19-25 (fraction III), 26-27 (fraction IV), 28-33 (fraction V) and 34-35 (fraction VI). Fraction I (327.3 mg) was subjected to an LCC (Ø: $2 \mathrm{~cm})$ using sephadex and $\mathrm{MeOH}$ as eluent obtaining 75 samples. After combining samples 63-75, PTLC $(20 \mathrm{~cm} \times 20 \mathrm{~cm} \times 0.25 \mathrm{~mm}$, silica gel F254, AcOEt:acetone: $\mathrm{CH}_{2} \mathrm{Cl}_{2}: \mathrm{MeOH}$ (1:1:1:1), $\mathrm{v} / \mathrm{v} / \mathrm{v} / \mathrm{v}$ in $\mathrm{NH}_{3}$ atmosphere) was used to isolate ismine $(\mathbf{1}, 5.7 \mathrm{mg})$. No alkaloid was observed in the fraction II (205.0 mg). Fraction III (253.5 mg) was subjected to an LCC ( $\varnothing: 2 \mathrm{~cm})$ using sephadex and $\mathrm{MeOH}$ as eluent, obtaining 80 samples. After combining samples 13-25, homolycorine was obtained $(\mathbf{1 2}, 8.0 \mathrm{mg})$ and samples 64-83 were subjected to PTLC $(20 \mathrm{~cm} \times 20 \mathrm{~cm} \times 0.25 \mathrm{~mm}$, silica gel F254, AcOEt:acetone: $\mathrm{CH}_{2} \mathrm{Cl}_{2}: \mathrm{MeOH}$ (1:1:1:1), $\mathrm{v} / \mathrm{v} / \mathrm{v} / \mathrm{v}$ in $\mathrm{NH}_{3}$ atmosphere) isolating trisphaeridine (2, $7.7 \mathrm{mg}$ ). Fraction IV (1295.4 mg) was subjected to an LCC (Ø: $2 \mathrm{~cm}$ ) using sephadex and $\mathrm{MeOH}$ as eluent obtaining 150 samples. After combining samples 64-83, this subfraction was subjected to an LCC (Ø: $2 \mathrm{~cm})$, eluting with $n$-hexane gradually enriched with EtOAc $(0 \rightarrow 100 \%)$, $\mathrm{CH}_{2} \mathrm{Cl}_{2}$ and $\mathrm{MeOH}(1: 1,0 \rightarrow 50 \%)$, and then with $\mathrm{MeOH}$ $(0 \rightarrow 50 \%)$ obtaining 350 samples. After combining samples 153-198, PTLC $(20 \mathrm{~cm} \times 20 \mathrm{~cm} \times 0.25 \mathrm{~mm}$, silica gel F254, AcOEt:acetone: $\mathrm{CH}_{2} \mathrm{Cl}_{2}: \mathrm{MeOH}=1: 1: 1: 1$, $\mathrm{v} / \mathrm{v} / \mathrm{v} / \mathrm{v}$ in $\mathrm{NH}_{3}$ atmosphere) was used to isolate tazettine $(\mathbf{8}, 11.5 \mathrm{mg})$ and homolycorine $(\mathbf{1 2}, 2.1 \mathrm{mg})$. Fraction V (1863.5 mg) was subjected to an LCC (Ø: $2 \mathrm{~cm})$ using sephadex and $\mathrm{MeOH}$ as eluent, obtaining 250 samples. Samples 37-77, from fraction $V$, were subjected to another LCC (Ø: $1 \mathrm{~cm})$, using $50 \mathrm{~mL}$ of $n$-hexane:AcOEt (2:1), $200 \mathrm{~mL}$ of AcOEt: $\mathrm{CH}_{2} \mathrm{Cl}_{2}$ :acetone (2:2:1), $200 \mathrm{~mL}$ of AcOEt: $\mathrm{CH}_{2} \mathrm{Cl}_{2}$ :acetone:MeOH (2:2:1:1), $100 \mathrm{~mL}$ of acetone:MeOH (1:1) providing 110 samples. Samples 45-77 were subjected to PTLC $(20 \mathrm{~cm} \times 20 \mathrm{~cm} \times 0.25 \mathrm{~mm}$, silica gel F254, AcOEt:acetone: $\mathrm{CH}_{2} \mathrm{Cl}_{2}: \mathrm{MeOH}$ (1:1:1:1), $\mathrm{v} / \mathrm{v} / \mathrm{v} / \mathrm{v}$ in $\mathrm{NH}_{3}$ atmosphere) to obtain more tazettine (8, $22.5 \mathrm{mg}$ ) and more homolycorine $(\mathbf{1 2}, 4.5 \mathrm{mg})$. Samples 112-154, from fraction $\mathrm{V}$, were subjected to another LCC (Ø: $1 \mathrm{~cm})$ using $50 \mathrm{~mL}$ of $n$-hexane:AcOEt (2:1), $200 \mathrm{~mL}$ of AcOEt: $\mathrm{CH}_{2} \mathrm{Cl}_{2}$ :acetone (2:2:1), $200 \mathrm{~mL}$ of AcOEt: $\mathrm{CH}_{2} \mathrm{Cl}_{2}$ :acetone:MeOH (2:2:1:1), $100 \mathrm{~mL}$ of acetone:MeOH (1:1) providing 110 samples. Samples 81-99 were subjected to PTLC $(20 \mathrm{~cm} \times 20 \mathrm{~cm} \times 0.25 \mathrm{~mm}$, silica gel F254, AcOEt:acetone: $\mathrm{CH}_{2} \mathrm{Cl}_{2}: \mathrm{MeOH}(1: 1: 1: 1)$, v/v/v/v in $\mathrm{NH}_{3}$ atmosphere) to obtain more thisphaeridine (2, $2.2 \mathrm{mg}$ ). Samples 155-201, from fraction $\mathrm{V}$, was subjected to another LCC ( (2:1), $200 \mathrm{~mL}$ of AcOEt: $\mathrm{CH}_{2} \mathrm{Cl}_{2}$ :acetone (2:2:1), $200 \mathrm{~mL}$ of AcOEt: $\mathrm{CH}_{2} \mathrm{Cl}_{2}$ :acetone:MeOH (2:2:1:1), $100 \mathrm{~mL}$ of acetone: $\mathrm{MeOH}$ (1:1) providing 110 samples. From samples 82-101, it was observed a precipitate identified as ismine $(\mathbf{1}, 5.0 \mathrm{mg})$. No alkaloid was observed in the fraction VI $(1060.6 \mathrm{mg})$ and extract C. All isolated alkaloids were identified by comparing their spectroscopy data with those of alkaloids previously isolated and characterized described in literature. ${ }^{27,28,30-34}$

\section{X-ray experimental data}

$X$-ray intensity data were collected on a Bruker AXS Proteum X8 diffractometer using $\varphi$ and $\omega$ scans. The diffractometer was equipped with a Cu FR591 rotating anode and multilayer X-ray optics. An Oxford Cryosystems 700 controller was used to keep the temperature at $100 \mathrm{~K}$ during data collection. The APEX $2^{35}$ software was used to operate the diffractometer and planning the data collection strategy. The data were integrated using SAINT ${ }^{36}$ program and the correction for absorption effects was made using Gaussian numerical integration and scaled with SADABS $^{37}$ program. 
The crystal structure of tazettine (8) was solved by direct methods using the SHELXS ${ }^{38}$ program and refined by full-matrix least-squares method against the intensity data using SHELXL ${ }^{38}$ program. Anisotropic displacement parameters (ADP) were applied for all non-hydrogen atoms. Hydrogen atoms were observed by Fourier maps, and placed at geometrically calculated positions and refined using an appropriate riding model regard to the parent atom with $\mathrm{U}_{\mathrm{iso}}(\mathrm{H})=1.2 \mathrm{U}_{\mathrm{eq}}(\mathrm{C})$, displacement parameters, while the hydroxyl and methyl group were set using $\mathrm{U}_{\text {iso }}(\mathrm{H})=1.5 \mathrm{U}_{\text {eq }}\left(\mathrm{O}, \mathrm{C}_{\text {methyl }}\right)$. The solving and refinement were made with aid of the Olex $2^{39}$ program. The structure representations were done by ORTEP- $3^{40}$ and MERCURY ${ }^{41}$ programs. The crystallographic information and the structure data files for tazettine are deposited at Cambridge Crystallographic Data Centre (Supplementary Information section).

\section{P. falciparum in vitro culture and in vitro SYBR green assay}

The inhibitory activity of the seven isolated alkaloids and three extracts was evaluated against $P$. falciparum blood parasites of the 3D7 (chloroquine sensitive) and K1 (multidrug-resistant to the antimalarial drugs chloroquine, pyrimethamine and cycloguanil) strains. An aliquot of the 3D7 or K1 strain was obtained from the Malaria Research and Reference Reagent Resource Center (MR4-BEI Resources) and cultured as previously described, ${ }^{42}$ using complete RPMI medium (RPMI 1640 medium supplemented with $25 \mathrm{mM}$ hepes (pH 7.4), $21 \mathrm{mM}$ sodium bicarbonate, $11 \mathrm{mM}$ D-glucose, $3.67 \mathrm{mM}$ hypoxanthine, $40 \mu \mathrm{g} \mathrm{mL}^{-1}$ of penicillin-streptomycin and $0.5 \%(\mathrm{~m} / \mathrm{v})$ Albumax $\left.^{\circledR}\right)$. The compounds were previously solubilized in $0.05 \%$ dimethyl sulfoxide (DMSO) (v/v), distributed in duplicate in 96-well plates, using two-fold serial dilutions in complete RPMI medium to assay a range of concentrations $(10-0.152 \mu \mathrm{M}$ or $\left.10-0.152 \mu \mathrm{g} \mathrm{m}^{-1}\right)$. Synchronous ring-stage cultures of the parasite were added to the plate to a final parasitemia of $0.5 \%$ and hematocrit of $2 \%$. Previous ring-stage synchronization was performed by the sorbitol method. ${ }^{43}$

Each 96-well plate included positive and negative control wells, consisting of infected red blood cells without test compounds and non-infected red blood cells, respectively. Artesunate was used in each experiment as an antimalarial positive control. All compounds were tested in duplicate in two independent experiments. The effects of the samples on parasite growth were measured through the $\mathrm{SYBR}^{\circledast}$ green assay. ${ }^{44}$ Briefly, the medium was removed, followed by addition of $1 \mathrm{X}$ PBS (phosphate buffered saline) and incubation for $30 \mathrm{~min}$ with lysis buffer solution [TRIS, ultra-pure $20 \mathrm{mM}$, pH 7,5; EDTA 5 mM ultrapure; Saponin $0.008 \%$ m/v; Triton X-100 0.08\% v/v; water Type I] and $\mathrm{SYBR}^{\circledR}$ green I DNA stain (in a 1:20000 dilution). Fluorescence was aquired on a fluorimeter (SpectraMax 340 PC 384) at 485/535 nm. The fluorescence of each well was used to calculate the normalized viability in comparison to the positive (100\% viability) and negative (0\% viability) control wells. The half-maximal sample inhibitory concentration $\left(\mathrm{IC}_{50}\right)$ was estimated by curve fitting using software from the OriginLab Corporation (USA) and comparing to the parasite growth in the drug-free medium. The reported antiplasmodial activities (Tables 2 and 3) are the mean values of two independent experiments. The assessed $\mathrm{IC}_{50}$ values are based on the mass of the isolated compounds or extracts dissolved in DMSO.

Cytotoxicity tests using immortalized liver cells by MTT assay

The cytotoxicity of the all samples was evaluated in a human hepatoma cell line (HepG2, obtained from American Type Culture Collection (ATCC; Manassas, VA, USA)) using cells cultured in $75 \mathrm{~cm}^{2}$ sterile flasks containing RPMI-1640 medium (supplemented with $10 \%$ heat-inactivated fetal bovine serum and $40 \mathrm{mg} \mathrm{L}^{-1}$ gentamicin) under a $5 \% \mathrm{CO}_{2}$ humidified atmosphere at $37^{\circ} \mathrm{C}$. When confluent, the cell monolayer was washed with culture medium, trypsinized, distributed in a flat-bottomed 96 -well plate $\left(5 \times 10^{4}\right.$ cells per well $)$ and incubated for $24 \mathrm{~h}$ at $37^{\circ} \mathrm{C}$ for cell adherence (method adapted from Denizot and Lang). ${ }^{45}$ The samples $(20 \mu \mathrm{L})$ at various concentrations (400-0.5 $\mu \mathrm{M}$ or $400-0.5 \mu \mathrm{g} \mathrm{mL}-1$ in two-fold serial dilutions) were placed in the 96 -well plates, incubated with the cultured cells for $24 \mathrm{~h}$ under a $5 \% \mathrm{CO}_{2}$ atmosphere at $37^{\circ} \mathrm{C}$, and then the 3-(4,5-dimethylthiazol2-yl)-2,5-diphenyltetrazolium bromide (MTT) solution ( $5 \mathrm{mg} \mathrm{mL}^{-1} ; 20 \mu \mathrm{L}$ per well for $3 \mathrm{~h}$ ) was used to evaluate the mitochondrial viability. Each plate included positive control wells without addition of test compounds. The supernatants were carefully removed and $100 \mu \mathrm{L}$ of DMSO were added to each well and mixed to solubilize the formazan crystals. The optical density was determined at $570 \mathrm{~nm}$. The cell viability was expressed as the percentage of the control absorbance in the untreated cells after subtracting the appropriate background. The reported cytotoxic potency (Table 3) is the mean value of two independent experiments.

\section{Results and Discussion}

\section{Chemical analysis of alkaloids}

Lycorine (11) was the major alkaloid obtained $(547.2 \mathrm{mg}, 0.37 \% \mathrm{~m} / \mathrm{m})$ followed by tazettine $(\mathbf{8}, 114.3 \mathrm{mg}$, 
$0.08 \% \mathrm{~m} / \mathrm{m})$, homolycorine $(\mathbf{1 2}, 33.4 \mathrm{mg}, 0.02 \% \mathrm{~m} / \mathrm{m})$, 3-epi-macronine $(\mathbf{1 3}, 28.9 \mathrm{mg}, 0.02 \% \mathrm{~m} / \mathrm{m})$, trisphaeridine $(\mathbf{2}, 28.8 \mathrm{mg}, 0.02 \%)$, ismine $(\mathbf{1}, 23.8 \mathrm{mg}, 0.02 \% \mathrm{~m} / \mathrm{m})$ and albomaculine (14, $15.5 \mathrm{mg}, 0.01 \%)$.

The GC-MS approach applied to enriched-alkaloidal fractions from Worsleya procera (Table 1) allowed us to distinguish 18 alkaloids from the complex mixture of metabolites, been that 15 of them were identified by comparison of their GC-MS spectra and Kovats retention indices with our in-home library database (Figure 1). The alkaloids pretazettine (expressed as tazettine) and albomaculine were the main components from the $n$-Hex extract, while galanthine and again pretazettine were the major alkaloids from the EtOAc extract. The observed percentages in both extracts were approximately 15 and $20 \%$ of TIC (total ion current). The labile alkaloid pretazettine undergoes a fast rearrangement to tazettine after acid-base extraction and under GC-MS conditions, and then it is detected as tazettine. ${ }^{29}$ Lycorine and galanthindole showed a remarkable percentage at the EtOAc extract (13.2 and $12.8 \%$, respectively), although it showed no detection and less than $1 \%$ of TIC from $n$-Hex fraction, respectively. Homolycorine, which is biogenetically related with the lycorine skeleton, displayed 8.9 and $4.8 \%$ of TIC from $n$-Hex and EtOAc fractions, respectively. The alkaloids 3-epi-macronine showed $6.1 \%$ of TIC from $n$-Hex extract, although it was detected only as traces from EtOAc fraction.

Concerning the minor components, the considered catabolic product from haemanthamine-type skeleton ismine was detected from the $n$-Hex extract at percentages of 3.2 and $5.8 \%$ of TIC, respectively. The related homolycorine-type alkaloid $O$-methyllycorenine was only detected from $n$-Hex extract, but at low amount (4.0\%). The alkaloids belonging to the homolycorine series displaying a typical EI-MS fragmentation pattern which is featured by a retro-Diels-Alder rearrangement generated two fragments: one, the most representative, illustrates the pyrrolidine ring (along with the substituents in position 2), and the other one (a less abundant fragment) encompasses the aromatic lactone or hemilactone moiety. ${ }^{46}$ Furthermore, a noteworthy feature is the low abundance of the molecular ion peak in all alkaloids with a double bound $\Delta .{ }^{3,4}$ In this attempt, some alkaloids were detected belonging to the homolycorine-type skeleton, even though they were not identified using only GC-MS techniques. Besides, an ungwedine derivative was detected by GC-MS, but just as traces. Further efforts must be applied in terms of collection of plant material, acid-base extraction and purification steps for isolation of these minor components and complete structure characterization using other spectroscopic techniques.

\section{X-ray analysis}

During the work with the isolation of Worleya procera chemical compounds, tazettine (8) crystallized spontaneously. This led us to an in-depth study on the crystallographic structure of this compound.

A single-crystal X-ray diffraction experiment of tazettine (8) was carried out to determine the absolute configuration of the molecule. In this sense, we initially carried out a low temperature single crystal X-ray diffraction experiment using $\mathrm{Cu}$ radiation. The crystallographic structure of the compound $\mathbf{8}$ is already known. However, structure was reported with error on absolute-configuration
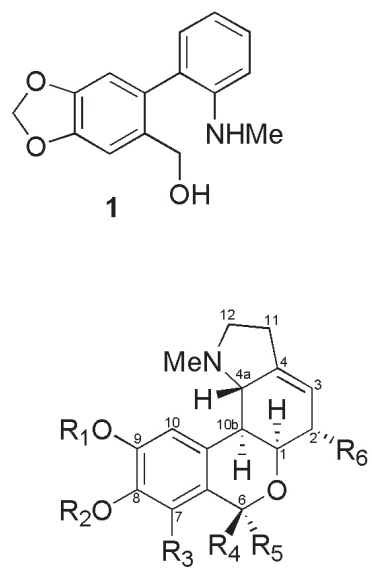

$5 \mathrm{R}_{1}=\mathrm{R}_{2}=\mathrm{Me}, \mathrm{R}_{3}=\mathrm{H}, \mathrm{R}_{4}=\mathrm{H}, \mathrm{R}_{5}=\mathrm{OMe}, \mathrm{R}_{6}=\mathrm{H}$

$6 \mathrm{R}_{1}=\mathrm{R}_{2}=\mathrm{Me}, \mathrm{R}_{3}=\mathrm{OMe}, \mathrm{R}_{4}=\mathrm{H}, \mathrm{R}_{5}=\mathrm{OMe}, \mathrm{R}_{6}=\mathrm{H}$

$12 \mathrm{R}_{1}=\mathrm{R}_{2}=\mathrm{Me}, \mathrm{R}_{3}=\mathrm{H}, \mathrm{R}_{4}+\mathrm{R}_{5}=\mathrm{O}, \mathrm{R}_{6}=\mathrm{H}$

$14 \mathrm{R}_{1}=\mathrm{R}_{2}=\mathrm{Me}, \mathrm{R}_{3}=\mathrm{OMe}, \mathrm{R}_{4}+\mathrm{R}_{5}=\mathrm{O}, \mathrm{R}_{6}=\mathrm{H}$

$15 \mathrm{R}_{1}+\mathrm{R}_{2}=\mathrm{CH}_{2}, \mathrm{R}_{3}=\mathrm{H}, \mathrm{R}_{4}+\mathrm{R}_{5}=\mathrm{O}, \mathrm{R}_{6}=\mathrm{OH}$<smiles>CN1Cc2cc3c(cc2-c2ccccc21)OCO3</smiles>

3<smiles></smiles>

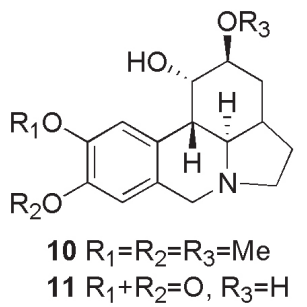<smiles>Cn1ccc2cccc(-c3cc4c(cc3CO)OCO4)c21</smiles><smiles>[R]CC1(NC)OC([R2])([R3])c2cc3c(cc2[C@@]12C=C[C@@H](OC)C[C@H]2NCC)OCO3</smiles>

$8 \mathrm{R}_{1}=\alpha \mathrm{OH}, \mathrm{R}_{2}=\mathrm{R}_{3}=\mathrm{H}$

$9 \mathrm{R}_{1}=\beta \mathrm{H}, \mathrm{R}_{2}=\mathrm{OH}, \mathrm{R}_{3}=\mathrm{H}$

$13 \mathrm{R}_{1}=\beta \mathrm{H}, \mathrm{R}_{2}+\mathrm{R}_{3}=\mathrm{O}$

Figure 1. Alkaloids identified in Worsleya procera. 
in $1996^{47}$ because no accurate experiment was carried out. Then in $1998,{ }^{48}$ a more rigorous experiment at low temperature was reported, giving, therefore, a more accurate structure. In this work, the structural determination was conducted at $178 \mathrm{~K}$, facilitating the scattering and allowing a more reliable absolute structure determination. Indeed, Linden et al. ${ }^{48}$ refined their structure based on the comparison with the derivative $N$-methyltazettine iodide, ${ }^{49}$ once no meaningful anomalous scattering was observed for tazettine compound using Mo radiation.

Therefore, here we performed a meticulous experiment with $\mathrm{Cu}$ radiation at lower temperature $(100 \mathrm{~K})$ to avoid the hitch of the non-anomalous scattering observation in tazettine. This strategy allowed us to obtain well-defined Friedel pairs suitable to solve the absolute configuration with a coherent Flack parameter. ${ }^{50,51}$ It is important to mention that for a meaningful absolute structure characterization, the Flack parameter should be close to 0 (with significant errors also) when the correct absolute configuration over each chiral center is given correctly.

Regarding the molecular conformation, an $S$-configuration was observed in each chiral center during the refinement. In this way, the structure reported herein matches very well with the one reported by Linden et al. ${ }^{48}$ with a very low root mean square deviation value (RMS 0.00681). As discussed by Linden et al. ${ }^{48}$ all the structural parameters are in a normal range of expected values. The small differences between both structures are mainly due to the differences in the data collection temperature. The hydroxyl group (C6a-O6a) exhibits a bond length of $1.400(3) \AA$, which is a value lower

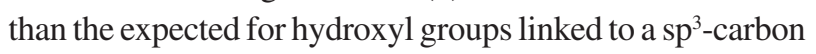
atom. ${ }^{52}$ Asymmetrical $\mathrm{C}-\mathrm{N}$ bonds were also observed over the $\mathrm{N}$-atom which adopts a $\mathrm{sp}^{3}$-pyramidalization, as pointed out Linden et al. ${ }^{48}$ Meanwhile, the bond vector of the methoxy group (O3-C14) showed an anti-orientation regarding the hydroxyl group, which was settled by the torsional angles $\mathrm{C} 2-\mathrm{C} 3-\mathrm{O} 3-\mathrm{C} 14$ and $\mathrm{C} 4-\mathrm{C} 3-\mathrm{O} 3-\mathrm{C} 14$ $\left(-171.75^{\circ}\right.$ and $66.57^{\circ}$, respectively).

Both the cyclohexene and the pyran rings exhibited distorted half-chair conformations. The cyclohexene ring was twisted over the $\mathrm{C} 4-\mathrm{C} 4 \mathrm{a}$ bond, while the pyran ring was twisted over the $\mathrm{C} 6 \mathrm{a}-\mathrm{O} 7$ bond. The pyrrolidine ring also showed a half-chair conformation twisted on C6a-C13b bond. Lastly, the 1,3-benzodioxole ring showed an almost planar conformation, except for the position of the $\mathrm{C} 11$ atom, which was slightly deviated $(0.20 \AA)$ from the mean plane of the remaining atoms. An ORTEP type view model of tazettine asymmetric unit showing the atom-labelling and an overlay of the tazettine structure described here with one reported structure by Linden et al. ${ }^{48}$ (red) can be seen in Figures 2a and 2b, respectively.

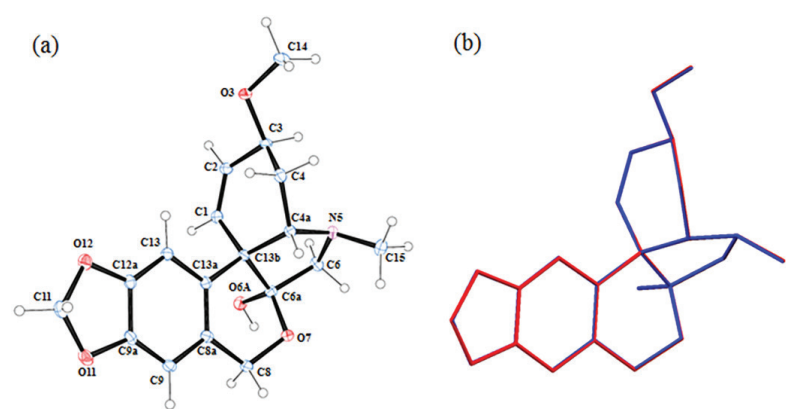

Figure 2. (a) ORTEP type view model of tazettine asymmetric unit showing the atom-labelling Thermal displacement ellipsoids are drawn at $50 \%$ probability level. Hydrogens atoms are drawn with arbitrary radii; (b) overlay of the tazettine structure (blue) described here with one reported structure by Linden $e t$ al. ${ }^{48}$ (red). Hydrogen atoms were omitted for the sake of clarity. The CSD ref. code RENRIL01 was assigned for the Linden et al. ${ }^{48}$ structure.

Tazettine crystallized in the non-centro symmetric orthorhombic space group $\mathrm{P} 22_{1} 2_{1}$. The hydroxyl group acted as a donor center of strong $\mathrm{OH} \cdots \cdot \mathrm{O}$ hydrogen-bonds with the methoxy groups of adjacent molecules along the crystallographic $b$ axes, giving raise to one-dimensional infinite chains with $\mathrm{C}(8)$ graph set. ${ }^{53}$ We observed weak $\mathrm{C}-\mathrm{H} \bullet \bullet \mathrm{N}$ interactions between one $\mathrm{C}-\mathrm{H}$ fragment of benzodioxole group and the $\mathrm{sp}^{3}$-pyramidal $\mathrm{N}$ atoms and could contribute to the crystal packing. Additionally, $\pi \cdots \bullet \pi$ interactions between the 1,3-benzodioxole fragments helped in the stacking of the tazettine molecules along the crystallographic $a$ axe. A stereographic view from the crystal packing and the main intermolecular interactions of tazettine crystal packing can be seen in the Figures 3 and 4 , respectively.

\section{Biological activity}

Many compounds found in Amaryllidaceae plants have antiplasmodial potential, ${ }^{10}$ and therefore, we assessed the biological relevance of the Worsleya procera root extracts by investigating the antiplasmodial potency of the samples. Thus, a total of 10 samples was tested against $P$. falciparum (3D7 strain, sensitive to chloroquine), including three extracts (A-C) and seven isolated compounds. The hexane (extract A) and ethyl acetate (extract B) fractions were active against the parasite, showing $\mathrm{IC}_{50}$ values of 1.3 and $0.8 \mu \mathrm{g} \mathrm{mL}-1$, respectively (Table 2 ), whereas the EtOAc: $\mathrm{MeOH}$ fraction (extract $\mathrm{C}$ ) was inactive under the assay condition. Next, we assessed the parasite growth inhibitory activity of the seven major isolated alkaloids to identify which extract components were related to the antiplasmodial activity (Table 3). We set a threshold concentration value of $10 \mu \mathrm{M}$ to identify the active compounds. Based on that, lycorine was the most potent P. falciparum inhibitor, with inhibitory activity in the low 
(a)

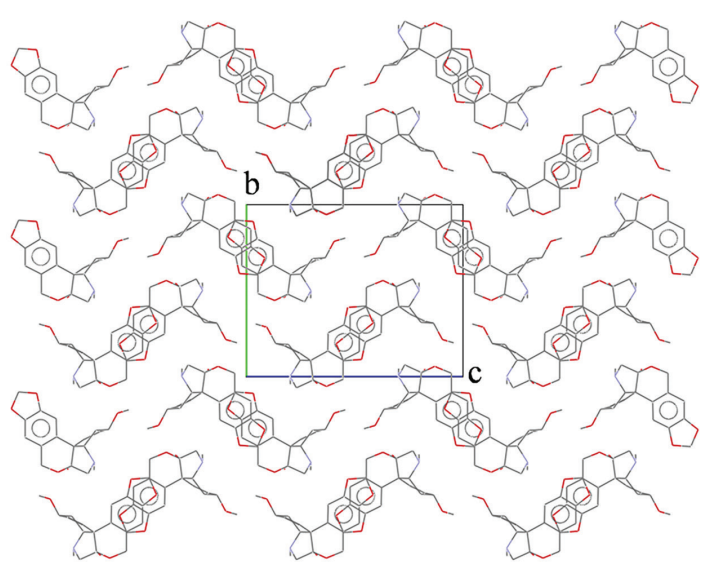

(b)

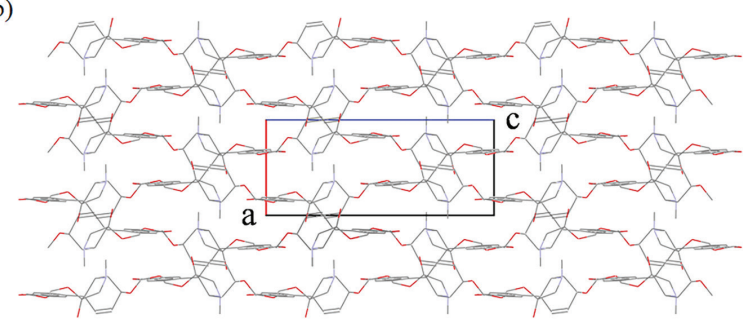

Figure 3. Stereographic view from the crystal packing along the (a) $a$ axis and (b) 1836655 axes; hydrogens atoms were omitted for the sake of clarity.

micromolar range $\left(\mathrm{IC}_{50}\right.$ value of $\left.2.5 \mu \mathrm{M}\right)$ (Table 3). This result is in agreement with previous data. ${ }^{10}$ Furthermore, lycorine was tested against the P. falciparum $\mathrm{K} 1$ strain (resistant to chloroquine, cycloguanil and pyrimethamine) to evaluate potential cross-resistance of the compound. As indicated in Table 3, the $\mathrm{IC}_{50}$ values against both sensitive and resistant strains were similar, thereby suggesting that lycorine's mechanism of action is distinct from those related to the $\mathrm{K} 1$ strain resistance.

Aiming to verify whether the antiplasmodial activities were related to cytotoxic effect, we evaluated the cytotoxicity of the active samples against HepG2 cells (hepatic human cells). A selectivity index (SI) above 10 generally indicates that the sample is well-tolerated by the cell. Interestingly, lycorine $\left(\mathrm{EC}_{50}>400 \mu \mathrm{M}\right)$ (median effective dose $\left.\left(\mathrm{EC}_{50}\right)\right)$, as well as the ethyl acetate and hexane extracts (both with $\mathrm{EC}_{50}>400 \mu \mathrm{g} \mathrm{mL}^{-1}$ ) were not cytotoxic under the experimental conditions, showing high selectivity indexes (SI values $>129>300$ and $>500$, respectively) (Tables 2 and 3).

The Worsleya procera (Lem.) Traub is yet largely unexplored in terms of chemical diversity. In this work, we showed that the roots of this plant contain compounds identified in other members of its family, such as Lycoris radiata. The Amaryllidaceae family of plants is of particular pharmacological interest in the field of natural products for the characteristic production of isoquinolinic alkaloids, a series of compounds with confirmed antitumoral, antimalarial and anti-inflammatory activity, among others. ${ }^{54}$ Other compounds obtained from this family are the cripowellins, isolated from plants of the Crinum genus, which have presented antiplasmodial potency in the nanomolar range, ${ }^{55}$ providing further evidence to the potential of these plants as a source of compounds with promising antiplasmodial activity.

(a)

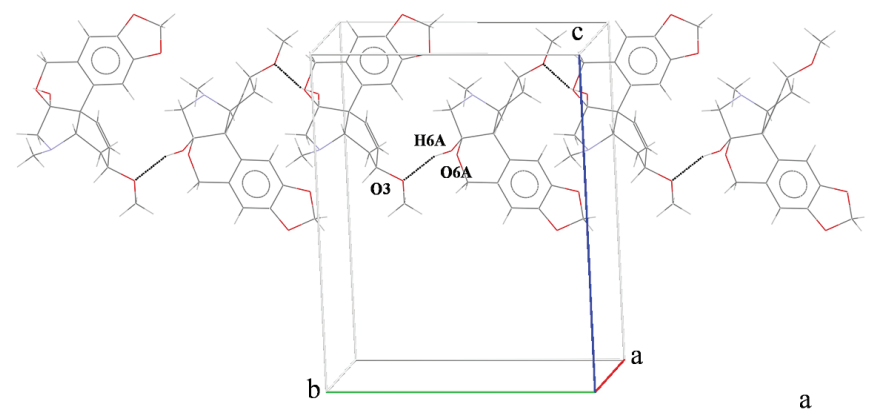

(b)

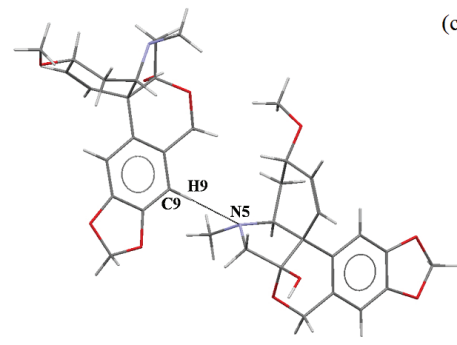

(c)

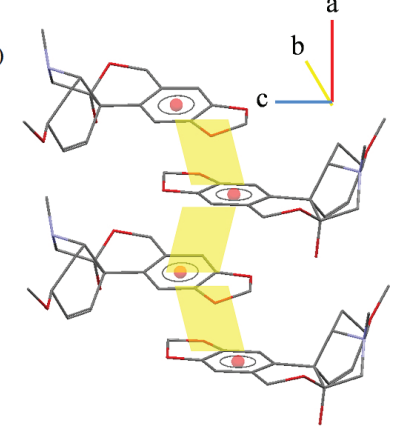

Figure 4. Main intermolecular interactions of tazettine crystal packing: (a) unidimensional hydrogen-bond chain along the crystallographic $b$ axe; (b) weak interaction of $\mathrm{C}-\mathrm{H} \bullet \bullet \mathrm{N}$ type, and (c) $\pi$-stacking of the 1,3-benzodioxole groups along the crystallographic $a$ axe. 
Table 2. Antiplasmodial and cytotoxic activities of extracts

\begin{tabular}{lccc}
\hline & Plasmodium falciparum & HepG2 & $\mathrm{SI}^{\mathrm{b}}$ \\
& $\left.\mathrm{IC}_{50}(\mathrm{CI} 95 \%) /(\mu \mathrm{g} \mathrm{mL})^{-1}\right)$ & $\mathrm{EC}_{50}(\mathrm{CI} 95 \%) /\left(\mu \mathrm{g} \mathrm{mL}^{-1}\right)$ & $>300$ \\
\hline Extract A & $1.3(1.2-1.4)$ & $>400$ & $>500$ \\
Extract B & $0.8(0.5-1.1)$ & $>400$ & nd \\
Extract C & $>20$ & nd & 71,500 \\
Artesunate & $0.004^{\mathrm{a}}(0.003-0.005)$ & $286^{\mathrm{a}}(186-386)$ & \\
\hline
\end{tabular}

HepG2: human hepatoma cells; $\mathrm{IC}_{50}$ : inhibitory concentration; $\mathrm{EC}_{50}$ : median effective dose; $\mathrm{CI} 95 \%$ : $95 \%$ confidence interval; ${ }^{\mathrm{a} e p o r t e d}$ values as $\mathrm{M}$ (average of two independent experiments); ${ }^{\mathrm{S}} \mathrm{SI}=\mathrm{EC}_{50} / \mathrm{IC}_{50}$; nd: not determined.

Table 3. Antiplasmodial and cytotoxic activities of isolated compounds

\begin{tabular}{|c|c|c|c|c|}
\hline \multirow{2}{*}{ Compound } & \multicolumn{2}{|c|}{ Plasmodium falciparum $\mathrm{IC}_{50} / \mu \mathrm{M}(\mathrm{CI} 95 \%)$} & \multirow{2}{*}{ HepG2 $\mathrm{EC}_{50} / \mu \mathrm{M}$} & \multirow{2}{*}{$\mathrm{SI}^{\mathrm{a}}$} \\
\hline & $3 \mathrm{D} 7$ & $\mathrm{~K} 1$ & & \\
\hline Lycorine & $2.5(1.7-3.3)$ & $3.1(2.2-4.0)$ & $>400$ & $>129$ \\
\hline Tazettine & $>10$ & nd & nd & nd \\
\hline 3-epi-Macronine & $>10$ & nd & nd & nd \\
\hline Homolycorine & $>10$ & nd & nd & nd \\
\hline Albomaculine & $>10$ & nd & nd & nd \\
\hline Ismine & $>10$ & nd & nd & nd \\
\hline Trisphaeridine & $>10$ & nd & nd & nd \\
\hline Artesunate & $0.004(0.003-0.005)$ & 0.007 & $286(186-386)$ & 71,500 \\
\hline
\end{tabular}

HepG2: human hepatoma cells; $\mathrm{IC}_{50}$ : inhibitory concentration; $\mathrm{EC}_{50}$ : median effective dose; $\mathrm{CI} 95 \%$ : $95 \%$ confidence interval; ${ }^{\mathrm{S} I}=\mathrm{EC}_{50} / \mathrm{IC}_{50} ;$ reported values are the mean of two independent experiments; nd: not determined.

\section{Conclusions}

Fifteen alkaloids were identified from the roots of the native species Worsleya procera, and seven of them were isolated. We obtained a crystal of the compound tazettine, and a detailed X-ray analysis was performed to obtain the unequivocal absolute configuration of this compound. The fractions and isolated compounds were tested in vitro against Plasmodium falciparum, and the compound lycorine showed antiplasmodial activity against sensate and resistant strains $\left(\mathrm{IC}_{50}\right.$ values of 2.5 and $3.1 \mu \mathrm{M}$, respectively). Moreover, the compound showed a low cytotoxicity profile, with a selectivity index greater than 100 . Our findings indicate that lycorine is a hit for antimalarial drug discovery.

\section{Supplementary Information}

Crystallographic data (excluding structure factors) for the structures in this work were deposited in the Cambridge Crystallographic Data Centre as supplementary publication number CCDC 1836655. Copies of the data can be obtained, free of charge, via www.ccdc.cam.ac.uk/conts/retrieving. html or from the Cambridge Crystallographic Data Centre, CCDC, 12 Union Road, Cambridge CB2 1EZ, UK; fax: +44 1223 336033. E-mail: deposit@ccdc.cam.ac.uk.

Supplementary information (NMR spectra, biological data and crystallographic parameters of tazettine) is available free of charge at http://jbcs.sbq.org.br as a PDF file.

\section{Acknowledgments}

This study was financed in part by the Coordenação de Aperfeiçoamento de Pessoal de Nível Superior (CAPES, Brazil) with Finance Code 001, by the National Council of Scientific and Technological Development (CNPq, Brazil) (grant 405330/2016-2 to R. V. C. G.) and by Foundation of Support to Research and Innovation of Espírito Santo (FAPES Universal No. 80708382/18).

We also thank Programa CYTED (416RT0511) and the São Paulo Research Foundation (FAPESP, Brazil) for funding the research (CEPID grant 2013/07600-3) and fellowships (2015/18192-9 to A. C. C. A. and 2017/04070-4 to J. O. S.), and Serrapilheira for funding the research (grant G-1708-16250 to R. V. C. G.). We also would like to acknowledge INCTBioNat (CNPq 465637/2014-0) for additional support, APA-Petrópolis by permission to collect the plant and NCQP-UFES.

\section{References}

1. http://www.who.int/malaria/publications/world-malariareport-2017/en/, accessed on April 04, 2019.

2. Amato, R.; Pearson, R. D.; Almagro-Garcia, J.; Amaratunga, C.; Lim, P.; Suon, S.; Sreng, S.; Drury, E.; Stalker, J.; Miotto, O.; Fairhurst, R. M.; Kwiatkowski, D. P.; Lancet Infect. Dis. 2018, 18, 337.

3. Newman, D. J.; Cragg, G. M.; J. Nat. Prod. 2016, 79, 629. 
4. Vieira, P. C.; J. Braz. Chem. Soc. 2015, 26, 1313.

5. Pinto, A. C.; Silva, D. H. S.; Bolzani, V. S.; Lopes, N. P.; Epifanio, R. A.; Quim. Nova 2002, 25, 45.

6. Pinto, A. C.; Rezende, C. M.; Garcez, F. R.; Epifanio, R. A.; Quim. Nova 2003, 26, 966.

7. Berlinck, R. G. S.; Borges, W. S.; Scotti, M. T.; Vieira, P. C.; Quim. Nova 2017, 40, 706.

8. Nozaki, J. R.; Kim, T.; Imakura, Y.; Kihara, M.; Kaboyashi, S.; Res. Virol. 1989, 140, 115.

9. Tanker, M.; Çitoglu, G.; Gümühek, B.; Hener, B.; Pharm. Biol. 1996, 34, 194

10. Şener, B.; Orhan, I.; Satayavivad, J.; Phytother. Res. 2003, 17, 1220.

11. Elgorashi, E. E.; Van Staden, J.; J. Ethnopharmacol. 2004, 90, 27.

12. Szlávik, L.; Gyuris, A.; Minárovits, J.; Forgo, P.; Molnár, J.; Hohmann, J.; Planta Med. 2004, 70, 871.

13. Eldeen, I. M. S.; Elgorashi, E. E.; Van Staden, J.; J. Ethnopharmacol. 2005, 102, 457.

14. Evidente, A.; Kireev, A. S.; Jenkins, A. R.; Romero, A. E.; Steelant, W. F. A.; Van Slambrouk, S.; Kornienko, A.; Planta Med. 2009, 75, 501 .

15. Osorio, E. J.; Berkov, S.; Brun, R.; Codina, C.; Viladomat, F.; Cabezas, F.; Bastida, J.; Phytochem. Lett. 2010, 3, 161.

16. Cheesman, L.; Nair, J. J.; Van Staden, J.; J. Ethnopharmacol. 2012, 140, 405.

17. Nair, J. J.; Van Staden, J.; J. Ethnopharmacol. 2014, 151, 12.

18. Dutilh, J. H.; Fernandez, E. P.; de Penedo, T. S. A.; de Moraes, M. M. V.; Messina, T.; Amaryllidaceae, $1^{\mathrm{a}}$ ed.; Andrea Jakobsson: Rio de Janeiro, Brasil, 2013.

19. Song, J. H.; Zhang, L.; Song, Y.; Fitoterapia 2014, 95, 121.

20. Liu, Z. M.; Huang, X. Y.; Cui, M. R.; Zhang, X. D.; Chen, Z.; Yang, B. S.; Zhao, X. K.; Fitoterapia 2015, 101, 188.

21. http://floradobrasil.jbrj.gov.br/reflora/floradobrasil/FB43, accessed on April 04, 2019.

22. Traub, H. P.; Herbertia 1940, 6, 118.

23. Martinelli, G.; Rodriguésia 1984, 36, 65.

24. Meerow, A. W.; Fay, M. F.; Guy, C. L.; Li, Q. B.; Zaman, F. Q.; Chase, M. W.; Am. J. Bot. 1999, 86, 1325.

25. Ministério do Meio Ambiente; Portaria No. 443, de 17 de dezembro de 2014, Diário Oficial da União, Brasília, DF, 18/12/2014 seção 1, p. 110-121, http://cncflora.jbrj.gov.br/ portal/static/pdf/portaria_mma_443_2014.pdf, accessed on April 04, 2019

26. http://floradobrasil.jbrj.gov.br/jabot/floradobrasil/FB33556, accessed on April 04, 2019.

27. Bessa, C. D. P. B.; de Andrade, J. P.; Oliveira, R. S.; Domingos, E.; Santos, H.; Romão, W.; Bastida, J.; Borges, W. S.; J. Braz. Chem. Soc. 2017, 28, 819.

28. de Andrade, J. P.; Guo, Y.; Font-Bardia, M.; Calvet, T.; Dutilh, J. H.; Viladomat, F.; Codina, C.; Nair, J. J.; Zuanazzi, J. A. S.; Bastida, J.; Phytochemistry 2014, 103, 188.
29. de Andrade, J. P.; Pigni, N. B.; Torras-Claveria, L.; Berkov, S.; Codina, C.; Viladomat, F.; Bastida, J.; J. Pharm. Biomed. Anal. 2012, 70, 13 .

30. Ghosal, S.; Kumar, Y.; Singh, S.; Phytochemistry 1984, 23, 1167.

31. Bastida, J.; Llabrés, J. M.; Viladomat, F.; Codina, C.; Rubiralta, M.; Feliz, M.; J. Nat. Prod. 1987, 50, 199.

32. Kihara, M.; Koike, T.; Imakura, Y.; Kida, K.; Shingu, T.; Kobayashi, S.; Chem. Pharm. Bull. 1987, 35, 1070.

33. Suau, R.; Gómez, A. I.; Rico, R.; Phytochemistry 1990, 29, 1710.

34. Likhitwitayawuid, K.; Angerhofer, C. K.; Chal, H.; Pezzuto, J. M.; Cordell, G. A.; J. Nat. Prod. 1993, 56, 1331.

35. APEX2 software version 2.1-0; Bruker AXS Inc. Madison, 2004.

36. SAINT software version 7.46a; Bruker AXS Inc. Madison, 2004.

37. Sheldrick, G. M.; SADABS software; University of Göttingen, Germany, 1996.

38. Sheldrick, G. M.; Acta Crystallogr., Sect. C: Struct. Chem. 2015, 71,3 .

39. Dolomanov, O. V.; Bourhis, L. J.; Gildea, R. J.; Howard, J. A. K.; Puschmann, H.; J. Appl. Crystallogr. 2009, 42, 339.

40. Farrugia, L.; J. Appl. Crystallogr. 1997, 30, 565.

41. Macrae, C. F.; Bruno, I. J.; Chisholm, J. A.; Edgington, P. R.; McCabe, P.; Pidcock, E.; Rodriguez-Monge, L.; Taylor, R.; van de Streek, J.; Wood, P. A.; J. Appl. Crystallogr. 2008, 41, 466.

42. Trager, W.; Jensen, J. B.; Science 1976, 193, 673.

43. Lambros, C.; Vanderberg, J. P.; J. Parasitol. 1979, 65, 418.

44. Smilkstein, M.; Sriwilaijaroen, N.; Kelly, J. X.; Wilairat, P.; Riscoe, M.; Antimicrob. Agents Chemother. 2004, 48, 1803.

45. Denizot, F.; Lang, R.; J. Immunol. Methods 1986, 89, 271.

46. Bastida, J.; Lavilla, R.; Viladomat, F.; The Alkaloids; Elsevier: Amsterdam, Netherlands, 2006.

47. Ide, S.; Șener, B.; Temizer, H.; Könükol, S.; Cryst. Res. Technol. 1996, $31,617$.

48. Linden, A.; Akineri, G.; Noyan, S.; Gozler, T.; Hesse, M.; Acta Crystallogr., Sect. C: Struct. Chem. 1998, 54, 1653.

49. Sato, T.; Koyama, H.; J. Chem. Soc. B 1971, 1070.

50. Flack, H.; Acta Crystallogr., Sect. A: Found. Adv. 1983, $39,876$.

51. Flack, H. D.; Bernardinelli, G.; Acta Crystallogr., Sect. A: Found. Adv. 1999, 55, 908.

52. Allen, F. H.; Watson, D. G.; Brammer, L.; Orpen, A. G.; Taylor, R.; International Tables for Crystallography book series, vol. C; Springer: Dordrecht, Netherlands, 2006, ch. 9.5.

53. Etter, M. C.; Acc. Chem. Res. 1990, 23, 120.

54. Bastida, J.; Berkov, S.; Torras, L.; Pigni, N. B.; de Andrade, J. P.; Martínez, V.; Codina, C.; Viladomat, F.; Recent Advances in Pharmaceutical Sciences; Transworld Research Network: Kerala, India, 2011, ch. 3, p. 65-100.

55. Presley, C. C.; Krai, P.; Dalal, D.; Su, Q.; Cassera, M.; Goetz, M.; Kingston, D. G. I.; Bioorg. Med. Chem. 2016, 24, 5418.

Submitted: December 28, 2018 Published online: April 11, 2019 